\title{
A WELCOME MESSAGE FROM THE EDITORS
}

Dear Readers,

We take great pleasure in welcoming you to our new journal, International Journal of Child, Youth and Family Studies. We have created this publication with the intention of providing a space for the generation of knowledge, dialogue, critique, debate, and collaboration among an international community of child, youth, family and community practitioners and scholars. The immediacy of e-based publication makes it possible for us all to be fully connected to each other and to developments in our field and to be directly involved in ongoing knowledge construction. Our journal is independent of corporate demands and the overlay of profit-making and profit-taking and we can therefore invite you to be full participants in the creative process that we are undertaking together.

Our vision is to create a high-quality publication that will be relevant, challenging, thought-provoking, and inclusive of a diverse range of voices and perspectives, including graduate students, academic researchers and scholars, policy-makers, and child, youth and family serving practitioners. We welcome original research, theoretical contributions, reviews of the literature, critical commentaries, case studies, book reviews, and works-inprogress.

We are extremely pleased that our inaugural journal offering: International Journal of Child, Youth and Family Studies, Volume One, Number One and Number Two, edited by Guest Editors, Michel Vallée and Tullio Caputo from Carleton University’s Department of Sociology and Anthropology, will appear simultaneously as two special electronic issues and a hard copy book entitled, Reflecting on Crime Prevention and Youth Justice in Canada. The book can be ordered directly from our web site upon the electronic publication of both journal issues. It is our intention from time to time, to offer guest edited special issues as books as well as journal offerings. We do this in order to support access and diversity in the ever narrowing corporatized world of academic publication.

We are delighted that you are joining us as readers and hope you will also join us as contributors.

Sibylle Artz, Ph.D

Jennifer White, Ed.D 